\title{
Determinants of Banking Competition in Morocco and Evaluation of the Structural Reforms
}

\author{
Afifa Hakam \\ Department of economics, University Mohammed V Agdal, \\ Morocco. E-mail: afifahakam@yahoo.fr \\ Filali Adib Fatine \\ Department of economics, University Mohammed V Agdal, \\ Morocco. E-mail: filaliadib@live.fr \\ Firano Zakaria \\ Department of managment, University Mohammed V Agdal, \\ Morocco. E-mail: firanou@yahoo.fr
}

\begin{abstract}
The empirical results of this paper indicate that the degree of competition in the banking system is determined by several macroeconomic aggregates that describe the relevance of the policies implemented in financial Morocco. Thus, the result shows that there is a positive relationship between the index of competition and concentration there by verifies our theoretical perception. On another note, economic growth is negatively correlated with the competition, which unfortunately indicates that when there are sustained economic growth banks does not behave concurrently and try to retain their market share stimulated by a high concentration sector. This is also dependent on conditions in the credit market, which indicates that when the demand is constant, banks tend to have fewer competing behaviors. In addition, the development of positive market impact of competition which is consistent with liberal theory. Thus, the use of financial market intensifies competition between banks to produce services being able to attract more customers to compensate for those who chose the stock market. Finally, in the implementation of monetary policy, the indicator of interbank interest rate has a positive impact on competition.
\end{abstract}

Keywords: Competition; Concentration; Financial Stability; Public policy; Economic Growth JEL Classifications: D41; G21

\section{Introduction}

Having regard to the recent financial developments, we can conclude that the banking system is characterized by imperfect competition can be a source of vulnerability to economic and financial stability. The Moroccan banking system is composed of a small number of banks whose characteristics are imperfect competition prevail. Reforms since the early 90 s were intended to improve competition in the banking system; however, what is observed is that competition is maintained unchanged (see Panzar and Rosse indicator in annex 1). In view of this, several questions are to make about the effectiveness of economic policy that have been undertaken during the years 1990 and 2000 and aimed in particular to increase the degree of competition in the Moroccan banking system.

Generally, the banking environment must be characterized by an increased competition to make profit the economic agents from a capable efficient financial intermediation to facilitate the optimal allowance of the resources. The economic conditions and the public policies influence the evolution of the banking behaviors mainly and significantly affect the degree of competition and per effect of rebound the conditions of financing of the economy.

From this point of view, this final paper aims at answering central problems relating to the identification of the factors and determinants of competition in Morocco. In other words, this paper is devoted to an analysis of the effects of the macroeconomic factors on the degree of competition of the Moroccan banking system. On this register, the highlighting of these factors will be able to help with 
the formulation of a judgment as for the effectiveness of the policies undertaken by Morocco lasting more than 20 years.

This paper is structured in two large sections. The first transcribes the theoretical and empirical framework of the relation between competition and the economic conditions and described in detail the macroeconomic factors which can affect the degree of competition. The second section, as for it, is devoted to the presentation of an econometric model making it possible to put in prospect the determinants for competition Morocco.

\section{Determinants of Competition: Theoretical Aspects and Empirical Work}

The question of the determinants of banking competition was only marginally treated by the economic theory, because of complexity to identify the factors being able to influence the banking degree of competition. Also, financial liberalization, the paradigm dominating, was regarded as being the single mechanism which can help to found a capable competing banking system to produce positive externalities in favor of the economic agents.

\subsection{Positive Externalities of banking competition}

To have a competing banking system allows leading to an economic development supported by allowing an optimal allowance of the resources, an advantageous access to the finance departments and maintenance of financial stability. The existence of the banking system, as mechanism of intermediation thus makes it possible to facilitate the high financing of the investment plans with profitability and preserves the economic system of any skid which can put it in danger.

\subsubsection{Economic growth}

The banking environment exerts a big role and paramount in the financing of the economy through the distributed appropriations. Thus the increase in banking competition generates important macroeconomic profits which are the result of the reduction of the monopoly rents, and of the improvement of the efficiency in the banking environment which allow a reduction of the margins and costs banking and consequently a fall of interest rates and thus of the credit charges supporting the investment and stimulating growth. The increase in competition thus makes it possible to reduce interest rates significantly and to reduce the rates of profit of the firms to equalize it with the marginal costs. This is beneficial for the consumer and makes it possible to facilitate the circulation of capital.

In fact, increased competition improves the effectiveness of the firms. According to the theory of "the quiet life" of the monopoly (Calm life theory, John Hicks), the capacity of monopoly reduces the motivation of the managers of undertaking required the maximum effort, this theory does not make consensus with the glance even economic markets because a monopoly which does not endeavor to reduce its costs to the minimum loses in profits. Consequently, the arrival of new competitors supports the incentives to be most effective possible by fear to disappear from the market.

As in the majority of the sectors of the economy, the advantages of a competition in the financial sector resident in the profits of efficiency, the supply of products of better quality to the ultimate consumers, an addition of innovation, a fall of the prices and an improvement of international competitiveness. An intensification of competition makes it possible moreover efficient banks to enter on the market and to develop to with it, at the expense of the inefficient establishments. Also, an improvement of competition in the banking system supports the capable innovation to increase the effectiveness of the banking system and to present more opportunity for the economic agents. The innovation in terms of product allows inter alia increasing the quality of the services and reducing the costs of intermediation. Admittedly banking industry is different from other industries, but the channels of minimization of the production costs remain similar.

Besanko and Thakor (1992), in their theoretical work, showed that in the presence of heterogeneity of the banking products (differentiation innovation) the production costs of the services record falls significant and in parallel, the credit costs are registered with the rise, which makes it possible to improve allocative efficiency, because of the fall of the costs of capable capital to increase the banking credit recourse and to increase consequently the value added. For them, the more competitive banking systems lead to higher growth rates. In fact, when the barriers at the entry decrease, the wellbeing of the shareholders of the banks decreases whereas that of the depositors and the borrowers increases.

\subsubsection{Access to the financial services}

The principal interest of banking competition is to increase penetration rate financial, through an advantageous access to the finance departments. Competition encourages, indeed, the fall of the costs of financing and financial management and makes it possible to develop the produced quantities, 
which is translated positively on the economic agents. However, at the theoretical level this relation between competition and the access to the finance departments remain discussed. Thus, on the level of a monopolistic structure, where the capacity of market is more important, the financial access can be more advantageous have regard to the economies of scale which were released by the dominant firms and their innovating capacities in terms of product (see Petersen and Ragan, 1994). Indeed, in a competing structure, the banks cannot invest in their relationships to the customers and be interested only in some segments.

On another register, the existence of a less competing structure, and the predominance of some institutions, can limit the possibilities of negotiation of the customers because of the big parts held by the banks of the place. From this point of view, competition would be more advantageous for the economic agents and leaves less operation for the banks.

In relation to the access to the finance departments, the quality of information, or the superiority of the information produced by the banking system, is a seminal factor. The quality of information also depends on the degree of competition characterizing the banking system. Thus, a structure of imperfect competition whose concentration is high makes it possible to produce relevant information seen deployed technology, however, this structure is not beneficial with the small and medium-size companies since the distance with the large banks is significant. However, the competition of the banking system can induce an investment increased in the information systems making it possible to improve the access to the financing, with the detriment of the evaluation of the credit risks (Crisis of the subprime, 2008).

\subsubsection{Financial stability}

Another very important aspect of the advantages of competition is the reinforcement of stability. On this subject the controversies are always in presence and the relation between competition and stability remains on line with the current debates on the financial regulation. Thus, the bond between competition and stability remain a problem unsolved in theoretical and empirical work. Competition was always perceived aliant a negative effect on stability. Indeed, competition encourages the taking risk excessive on the side of the credit and thus contributes to raise the probability of defect of an financial institution. The subjacent idea is that the banks by carrying out important profits by the taking risk excessive can be more exposed with the financial risks. In the same way the innovation on the side of the credit makes it possible to thwart the stability and this through an incentive even more important with the taking risk.

Other theories confirm that competition can have positive effects on the stability of the system and this through the analysis of anticipations of the economic agents. In fact, the borrowers near the banks, profit from fierce competition between the banks in terms of tariffing and differentiation. This encourages them to take of advantage of credit and to reduce their behaviors of opportunism. In front of this situation the borrowers will be able to ask more for credit to profit from the action leverages and to have more margin of profitability.

In fact, in the broad sense, the oligopolistic structure contributed to the crisis; it led so that many banks are systematically important with the moral risk that comprised, as well as guarantees and an excessive taking risk. While a structure of market less oligopolistic should contribute to stability, a better prudential regulation should also limit the excessive taking risk and reduce the risk of instability more.

\subsection{Theoretical determinants and empirical involved work}

The determinants of competition make it possible to evaluate the relevance of the economic policies led to instigate and support competition in the banking system. Empirical and theoretical work was harnessed in particular to the measures of competition instead of devoting a place to the factors being able to affect banking competition.

\subsubsection{Involved theories}

On the theoretical level the determinants of competition are inspired by the theories of industrial engineering of measurement of competition. In this direction, several factors are able to influence the degree of competition, it acts in fact of: the structure of industry and the degree of contestableness.

Bikker et al., (2007) identify several factors affecting competition within the banking system, for which they work out a classification in terms of factors affecting supply and factors affecting.

Factors of the offer. The degree of concentration is normally favorable for the realization of important profit and limit less and less the level of competition of the banking system. However, a more dynamic vision considers than the concentration perhaps the result of a fierce competition, which 
is in conformity with the remarks of Marshall (1890). Also, the barriers with entered are major determinants of competition in the banking system and are recognized to be obstacles as for the development of the degree of competitiveness of the banking firms. In practice, the processes of liberalization have eliminate the formal barriers, but those abstract remain always present (economies of scale for example).

As, it is to be announced as on the level of banking industry, the evolution of technologies of information, the increase in the regulation and requirements lawful (for example IFRS, Basle II, Solvency II), the increase in the development costs of new products are factors which influence the competition of the banks and which oblige them to re-examine their behaviors and their invoicing policies.

In another register, the policies of innovation undertaken by the banks are often against competition since it is noted that more and more the process of innovation is accompanied by complexities in favor of the offered products to the consumers, which limits the degree of competition. Indeed, the economic agents in front of ignorance which they have towards the very sophisticated financial products, they do not answer any more the changes of price concerning these products, thus making lower the positive externalities of the financial innovation and reducing consequently the degree of competition.

Another factor of order shareholder is to be also underlined; it acts of participations crossed in competing banks. The existence of such a configuration can be against competition by supporting the policy of dividend compared to the policy of competition. It is to be announced in last spring that arrangements within the markets of the capital and the systems of payment and payments are often popular between the banks of the same place. This coordination increases certainly the efficiency of the markets of capital, but can force competition within the banking market.

Factors of the request. Factors related to the basic characteristics of the structure of banking industry influence the degree of competition. It acts in a great measurement of elasticity of the request which can have effects on the price level on the market and consequently on the degree of competition of industry. Also, the stability or the volatility of the request can have similar effects. Thus, a volatile request makes the price determination delicate and a consensus also, which supports competition and limit the possibilities of having an imperfect competition.

Within the same framework, the costs of substitutions of the finance departments within the banking structure are rather high and varied. The existence of these costs reduces the possibility of substituting the services on behalf of the consumers what can block competition within the banking system.

On another register, the furnished information's by the banks on the market become increasingly difficult to approach by the simple capable consumer to weaken their capacity of negotiation with the banks. In this direction, the process of development of consumer loyalty and attractively is based more on confidence than on the prices weighing thus strongly on banking competition. In parallel the existence or not of structure sheltering the consumers and the investors significantly affects the degree of competition within banking industry.

The whole of these above mentioned factors are unobservable and depend on the macroeconomic and financial conditions of each country. For that, several works gave more weight to the indicators of concentration and the indices of contestableness in order to explain the evolution of competition in the banking system. New approaches integrate also measurements of the efficiency of banking industry and macroeconomic indicators of performance. Good number of work integrated these indicators, by holding account also institutional and legislative aspects (see work of Angelini and Cetorelli (2003), Maudos and Nagore (2005), Fernandez and Guevara, and Al (2005), Carbó Valverde and Rodríguez Fernández (2007) and Fernández de Guevara and Maudos (2007), using the index of lerner, and Bikker aet al., (2007) and Claessens and Laeven (2004), use H of Panzar and Rosse).

For this purpose, several factors are potential determinants of competition and can influence the degree of competitiveness of banking industry. Bikker et al., (2007) counted five types of families being able to impact banking competition, it acts of:

- Variables of the structure of industry;

- Variables of contestableness;

- Variables institutional;

- Variables of financial substitution;

- Macroeconomic variables. 
Variables of structure. The structure influences competition significantly. Among the suggested indicators, it there a:

- Rates of concentration of the sector: The ratio of the five large banks as a first measurement of the concentration of the banking, definite market like the total market share of the five plus large banks in a given country, according to the total credit. The HHI can also be considered.

- Many banks: The degrees of concentration are negatively correlated with the number of banks, because of a well-known theoretical weakness of the degrees of concentration, namely their dependence with regard to the size of a country or a banking market. This gap was exceeded through the use of the number of banks in presence within industry.

- Opening to the foreign banks. One integrates the degree of opening of the banking system through the report/ratio of the credit of the foreign banks in the active total of the system.

Variables of contestableness. In reference to the theory of the contestable markets defined a potential relation between the barriers in the entry and the exit of industry and the degree of competition. The indicators which can be suggested are:

- Restrictions on the activities (bulk-heading): variables recalling the capacities of banks to carry out various activities with are considered, it acts in particular of their gone wallet, insurance or others.

- Restriction on the overseas investments: all variables describing the degree of opening as for the overseas investment can be taken into account.

Variables of financial substitution. Those describe the relation between the existing types of intermediation to knowing substitution between direct and indirect finance. Generally one can use:

- Market capitalization: the report/ratio of the market capitalization compared to the GDP is a recommended indicator.

- Insurance companies: The annual volume of the premiums of life insurance in fraction of the GDP is an indicator of competition coming from the nonbanking part of the financial sector.

Institutional variables. Describe overall the institutional and lawful involved directives:

- Indicators of change of regulation and liberalization. Often dummy variables or indices built to describe the decisional changes.

Macroeconomic variables. Economic developments of the country and the effects of the committed public policies recall. One generally considers:

- GDP per capita: like proxy for economic development and financier.

- Growth of the annual real GDP: the annual growth of the GDP (or the GDP in variation compared to its tendency) can be regarded as an economic indicator. Indeed, competition can be affected by the reaction of the banks to the dynamics of the business cycle.

- The rate of inflation. This variable can also describe the economic tensions and also the future prospects and it can also influence banking tariffing and consequently the degree of competition. It can also be used like a deflator for the GDP.

\subsubsection{Empirical work}

Work aiming at identifying the determinants of competition is very few. The contribution of Claessens and Laeven (2004) remains most important on the question. The two authors evaluate the relation between the indicator of Panzar and Rose and the indicators of activity, structure and lawful modes. Their conclusions are of seminal importance because of the rejection of the effects of the structure of the market on the degree of competition. Thus, they corroborate the contestable design with the detriment of that structuralist for 39 countries concerned with the study. Work of Bikker et al., (2007) arrive at the same results by adopting a broader sample with 76 countries over one period going from 1995 to 2004. They managed to apply a large range of tests to evaluate the robustness of their approach, in order to make sure that their results do not depend on the subjective choices as for the selected specification of the model

A certain number of study also showed that the factors such as the specific characteristics of the banks and the degree of financial decomposition and conglomeration have important effects on the degree of competition of the banking system. These studies did not use indicators of competition or structure, but make prevail the importance of endogenous specificities of the banking system. 
Other work affirms that the liberalization of the banking system also affects the degree of competition and improves competitiveness within the banking system. Thus, the reforms undertaken in order to improve the degree of liberalization of the banking system supports the competitiveness of the system and makes it possible to increase the social wellbeing. These are the work which is very numerous and militates in favor of financial liberalization. Thus, Strahan (2003), whose contribution is major on the question, advances arguments in favor of the deregulation and its interests for banking competition. On the same register, work of Demsetz and al. (1999) could propose the positive effects of these reforms and reorganizations consequently on the increase in competitiveness. The same reports were underlined in work on the European Union and on the experiment of the other countries by (BIS (2006)). These studies also put forward the relation between the degree of competition and the changes in the regulation. Thus, often the regulators are obliged to make measurements according to the profile of the banks to manage to encourage competition. Also, the regulation towards the foreign banks intensified competition by limiting the constraints on entered and the exits of industry.

Other studies on panels of country showed that the factors specific to the structure and the environment of the banking system have significant effects on competition. These factors are in fact the barriers at the entry and the exit, the bulk-heading of the activities and the limits of the informational exchange within banking industry. Barth et al., (2001), in a bearing work on 107 countries of different regulation, they manage to affirm that the very restrictive conditions of entry have a negative impact on efficiency and competition. On another register, Demirgüç-Kunt et al., (2004) note that the concentration of the banking environment has a negative effect on competition of the banking system of 77 countries integrated in the study, except for the case of the developed and strongly liberalized banking systems. Another fundamental indicator was tested to explain banking competition; it acts of the economic growth. Indeed, work of Claessens and Laeven (2005) regresses the index of measurement of competition, 16 banking structures, compared to the level of the industrial growth and manages to confirm that the economic growth is closely related to the degree of banking competition.

\section{Banking Competition in Morocco and Major Determinants}

The influence which is the framework and economic environment, financier and institutional on banking competition are checked on the theoretical and empirical level. The empirical studies that we presented in the preceding section made it possible to confirm this report. This section has as an interest to propose an empirical evaluation of this report.

In this direction, one proposes to detect the variables which can explain the evolution of the degree of competition in the Moroccan banking system. The subjacent interest of this analysis is to enable us to observe the relevance of the policies undertaken during the two last decades.

Since, the Nineties, Morocco fell under a process of liberalization aiming at abolishing the various constraints weighing on the financial system. Thus, with the reform of 1993 and that of 1996 and 2006, Morocco engaged indeed in a liberalization of the financial sectors, by adopting a new banking law and new regulations and financial regulations (for the reforms undertaken by Morocco to see the appendices).

Although these reforms formed the angular stone which has led to the development that the system in the last years knew, no evaluation of their impacts on the degree of competition was MENA. From this point of view, this section is on the point of answering this key question, in ways required to the decision maker's measurements to be foreseen and lead in order to improve the degree of competition of the Moroccan banking system.

\subsection{Stylized facts and data analyzes}

In the light of developments the theoretical of the relation between competition and economic conditions and institutional, in particular liberalization, it is largely allowed that the policies of liberalization and economic extension, have positive effects on the evolution of competition. Liberalization and a constant economic growth result in stimulating the competition and the promotion of the financial innovation.

The analyses of the Moroccan financial aggregates provide important reports as for the validity of this theoretical design as well on the national plan as on the regional shutter. On the internal plan, the evolutions of the fundamental indicators indicate a heterogeneous reality. However, on the regional plan, the reforms which undertook Morocco had of the positive effects on the position of the Moroccan banking system compared to the banking systems of the countries of the zone MENA. 


\subsubsection{On the national plan}

To evaluate the effects of the public policies in favor of banking competition in Morocco, several indicators can be analyzed. These indicators can be laminated in three big families namely ${ }^{1}$ :

- Indicators of structure

- Indicators of efficiency and performance

- Indicators of development

\subsubsection{Indicators of structure}

Come into effect of the structural reforms which knew Morocco since 1993 had impacts on the structure of industry which are very significant. The principal indicator of the structure of the banking system is the degree of concentration. Its analysis makes it possible to note that:

Following the reform of 1996, the concentration largely regressed to reach historical levels recording almost 48, however and as from year 2000 this level was bent to return to the situation of before 1996.

In the light of the reform of 2006, the report is opposite, after the coming into effect of the new banking law and of the new statutes of BAM and the reinforcement of the framework legislative supporting liberalization, the Moroccan banking system became more and more concentrated, and in particular after the advent of the international financial crisis. This is all the more worrying knowing that no reorganization took place since 2003-2004 (see figure 1).

Figure 1. Banking degrees of concentration

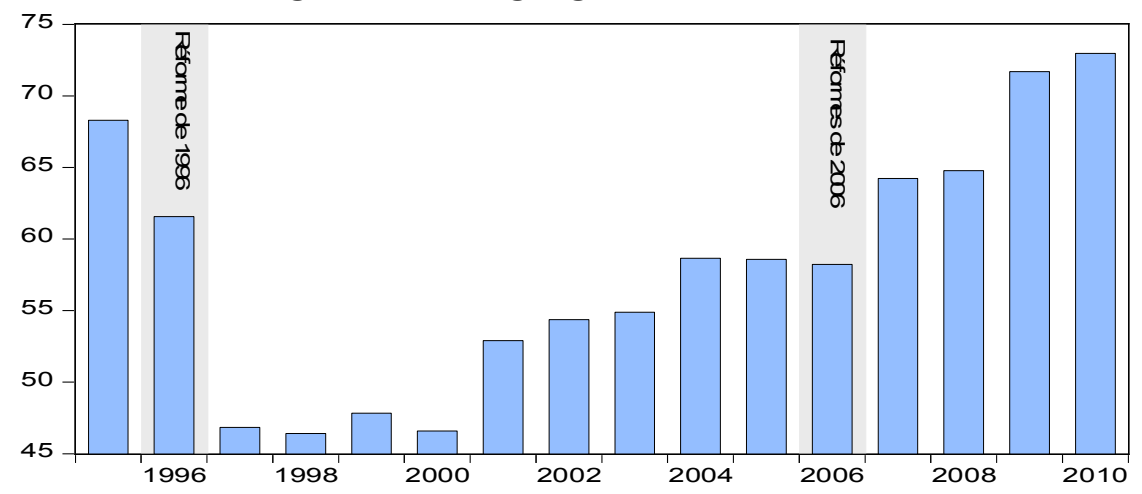

\subsubsection{Indicators of efficiency of performance}

In the field of efficiency, overall the Moroccan banking system recorded an improvement of its productive efficiency, by having debtor more and more low, capable rates to make profit the simple consumer from the gravitational finance departments.

On this register, the clear margin of interest of the banking system significantly dropped since the coming into effect of the law of 1996 and of this consolidated itself with the adoption of the reforms of 2006. Currently, the differential of the debtor and credit rates is in the neighborhoods of $3 \%$ and $4 \%$ testifying to an efficiency of the Moroccan banking system, under condition that is accompanied by a fall significant of the ratio of exploitation (figure 2).

Figure 2. Net interest margin

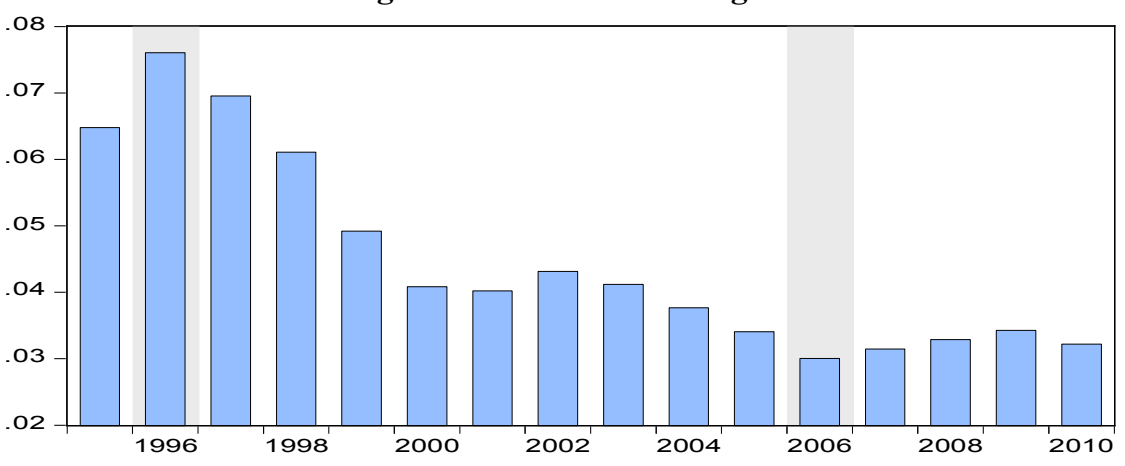

\footnotetext{
${ }^{1}$ Source of all data is World Bank Data Base.
} 
Concerning the ratio of exploitation, the indicator more the determinant, in term of efficiency and which indicates the function input-output of the banking system, the analysis of its evolution is not also obvious. The first reforms did not have impact on the costs of exploitation of the Moroccan banks, that is checked on the figure 3, however and from 2006 this report changed and the ratios of exploitation recorded a significant decrease, with a significant growth as from 2009, in answer to the crisis of lack of liquidity with which is confronted the Moroccan banking system. Within this framework, and by comparing the two indicators of efficiency (clear margin of interest and cost of exploitation) after the reforms of 2006, it is very difficult to allot the fall of the clear margin of interest to a rise in the efficiency of the Moroccan banking system.

Figure 3. Banking cost of exploitation

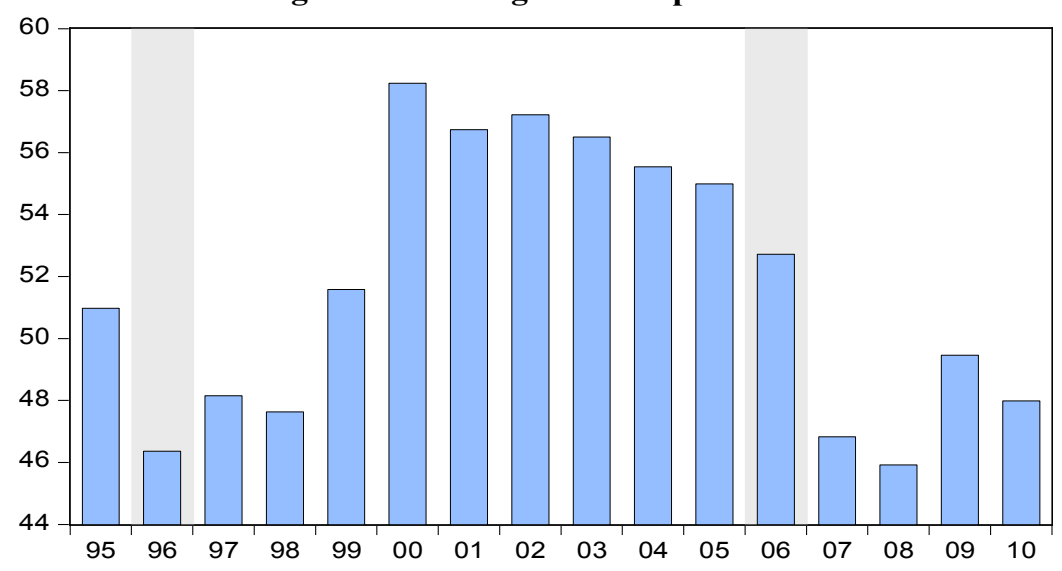

With regard to the profitability and the performance of the banking system, the Moroccan banking system is well located, but that cannot be to in any case to be allotted to the recasting of the legislative framework and the policy institutional, since the recorded levels remained quasi-stable. This is as well noted on the level of the return on assets and the return on equity (figure 3 and 4).

The yields are generally strongly correlated with the economic conjuncture and the growth prospects. This known as, the strong rates which were recorded since 2007 are due to positive perception as for the future prospects for the growth and to the sustained rhythms for the growth of the appropriations during these years.

\subsubsection{Indicators of development}

Although the reforms undertaken on the policies plan were of a modest effect on efficiency, the structure and the performance of the Moroccan banking system, they made it possible to develop the activity of intermediation and to register the banking environment like a sector far of the Moroccan economy.

Indeed, the banking credits significantly progressed to propel in that by the political reforms which put at the foreground the banking system. Thus, in 1996 the banking credits accounted for about $40 \%$ of the GDP, on the other hand starting from 1996 this rates did not cease increasing to reach in 2010 more than $85 \%$, with a more important growth rate after the coming into effect of the reforms of 2006 (figure 6 and 7).

Figure 4. Return on equity

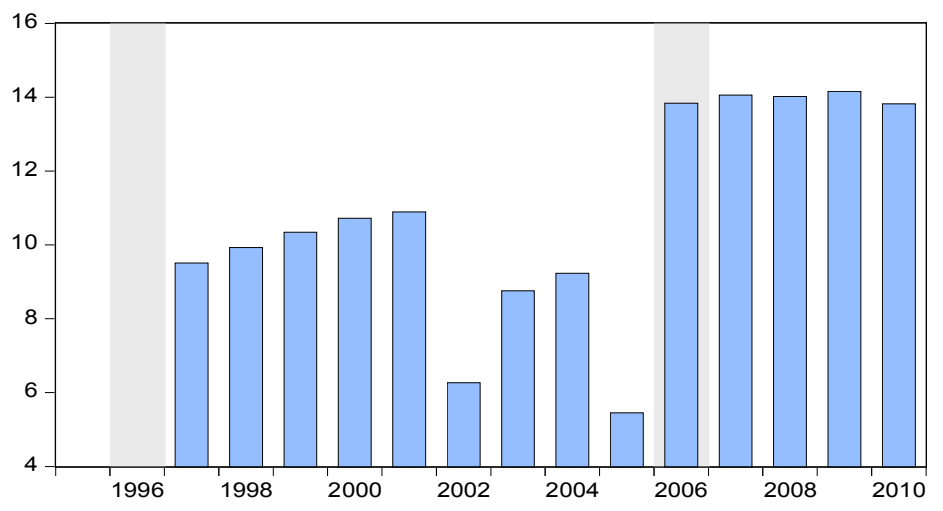


Figure 5. Return on assets

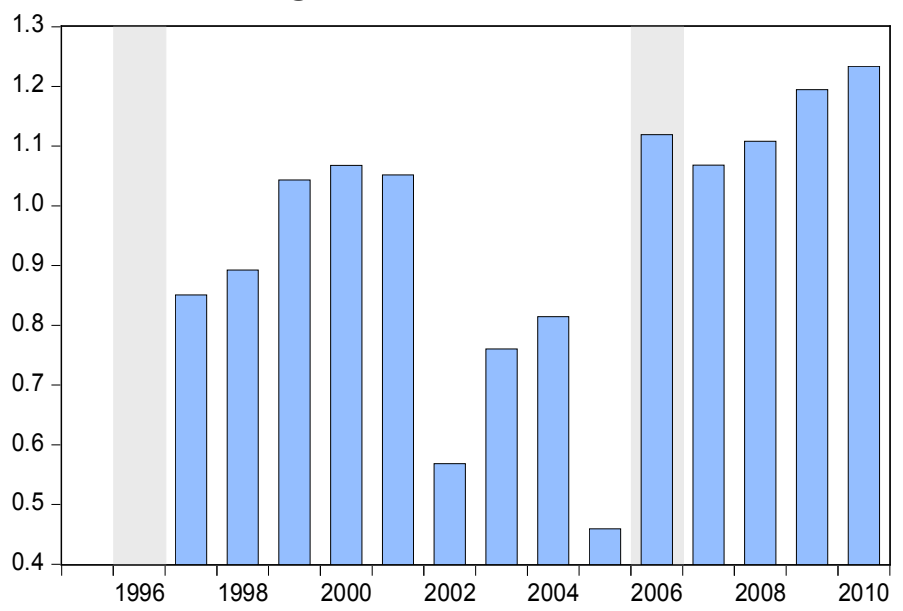

Figure 6. Banking assets /GDP

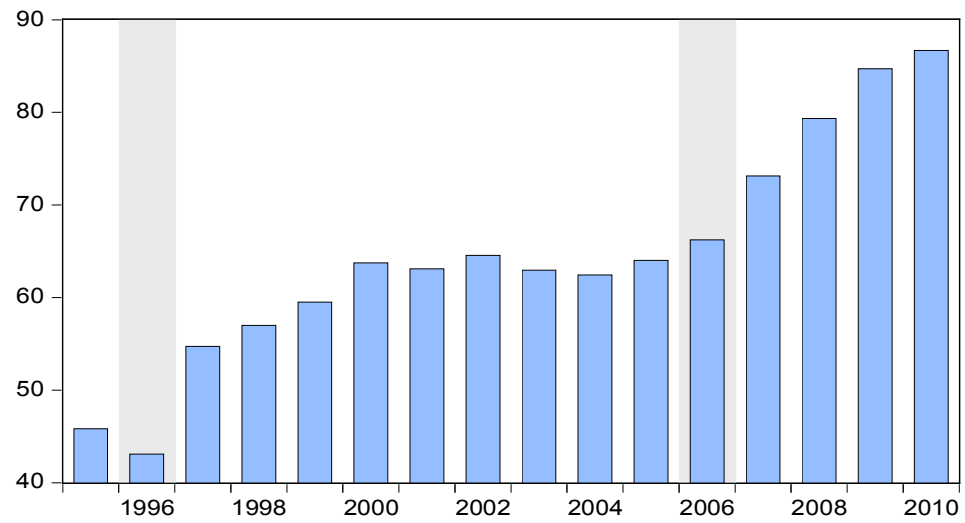

Within the same framework, since 1996 the Moroccan banking system continues to be the first financial mechanism of intermediation, thus profiting from the regulation framework supporting his implementation and its development. This makes it possible to confirm that the banking system monopolizes the majority of the activities of financing and the other finance mechanisms remain marginalized.

Figure 7. Banking assets/Total Financial assets

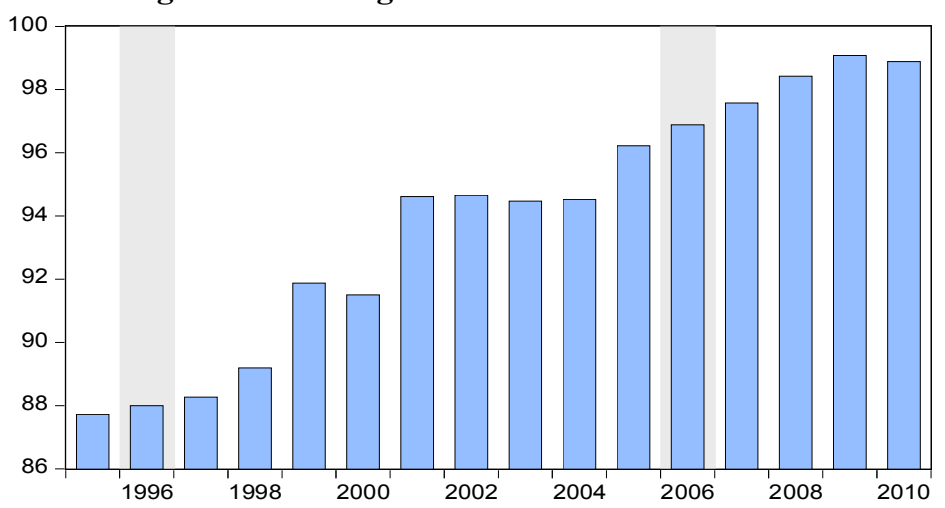

Taking into consideration this analysis, it is clear that the Moroccan banking system is characterized by a high concentration and the reforms undertaken since 1993 had only one marginal impact on competition. They were more beneficial for the development of the indirect intermediation and the traditional bank.

\subsubsection{On the regional plan}

Morocco fell under important reforms, as well on the lawful level as institutional, in order to position like a regional benchmark. 


\subsubsection{Indicators of the structure}

In terms of banking structure, the Moroccan banking system has a less comfortable position. It posts very high levels of concentration (indices of Lerner and concentration) compared to the other countries of the zone MENA (figure 8). On this register, one notes that the reforms undertaken could not attenuate this exponential evolution of the concentration.

Figure 8. Position of Morocco compared to MENA zone ${ }^{2}$ (structure) (exploitation cost, Lerner index and concentration index)
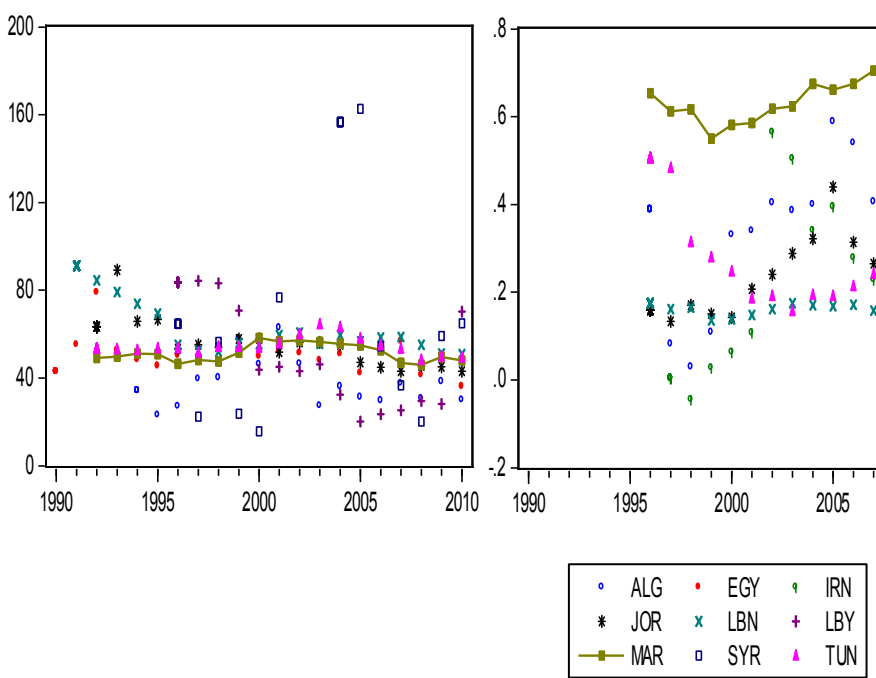

\subsubsection{Indicators of efficiency and performance}

On the level of the indicators of efficiency, the clear margin of interest of the Moroccan banking system remains highest compared to the other countries of the zone MENA and this since the beginning of the Nineties (figure 9). In the same wake, the outputs on credits and equities of the banks are also among highest of the zone MENA, thus making it possible to position Morocco like gravitational for the foreign investors. On the competing level, this should result in entered the more massive on the sector as well by national investors as international. However the difficulties in reaching (barriers with entered) the banking environment in Morocco continue to weigh on the system once again justifying this significant difference between the yields with the countries of the area.

Figure 9. Position of Morocco compared to MENA zone (Indicating profitability: ROA, net interest margin, ROE)
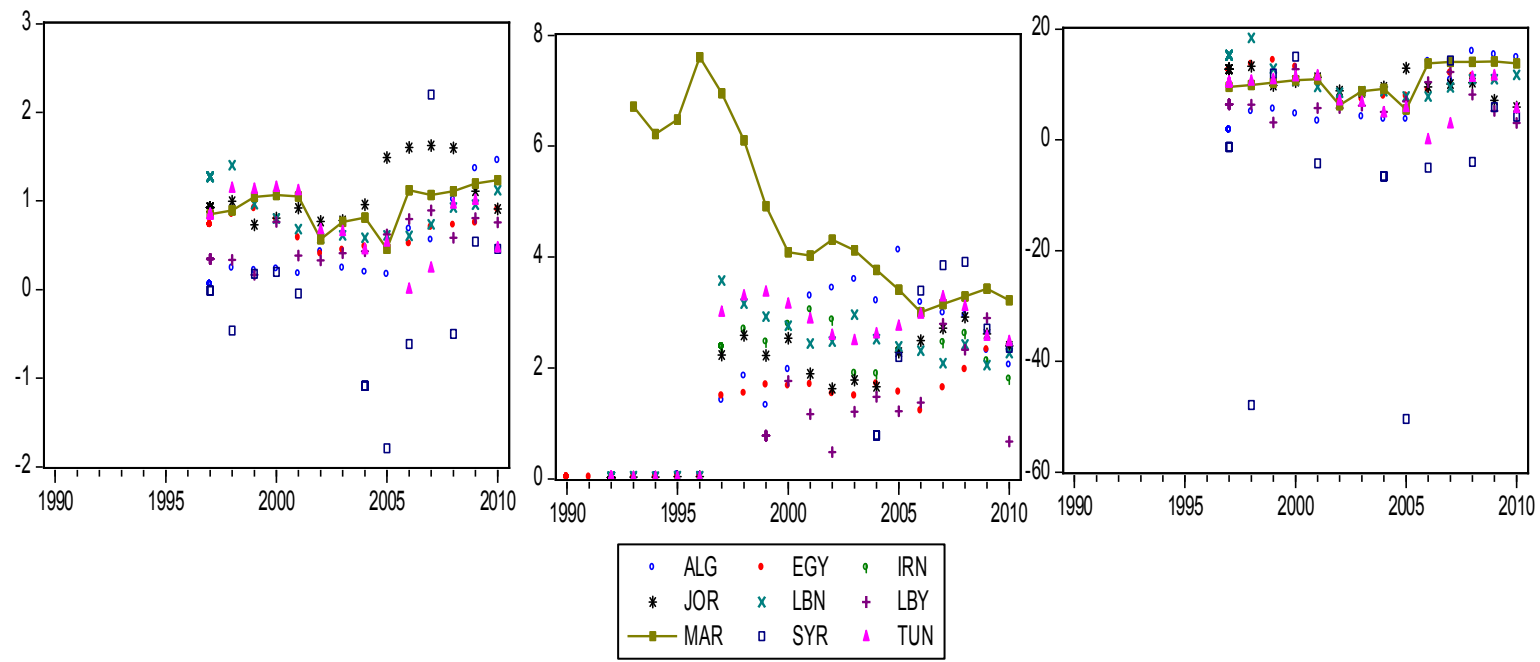

\footnotetext{
${ }^{2}$ ALG :Algeria,EGY : Egypt,IRN : Iran, JOR : Jordan, LBN : Lebanon, LBY :Libya, MAR: Morocco, SYR: Syria, TUN:Tunisia
} 


\subsubsection{Indicators of development and stability}

The development of the Moroccan banking system was more significant compared to the other countries of the area (figure 10). However in the field of direct finance, Morocco always records delay, in particular in front of Jordan which continues to record the levels more important than those which Morocco enjoys.

Figure 10. Position of Morocco compared to MENA zone (Indicating development capitalization gap and Credit to GDP)

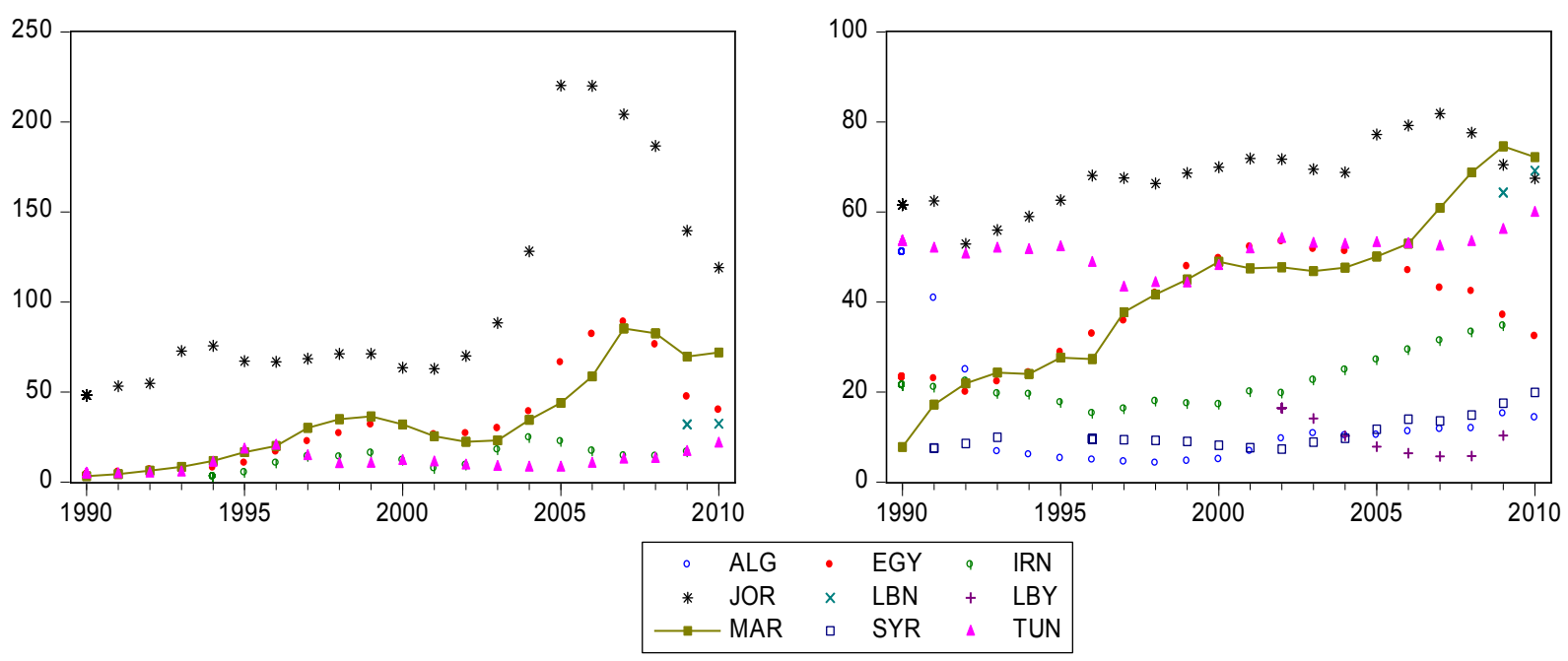

With regard to financial stability, the position of Morocco remains weak compared to the other countries. Thus on the level of the ratio of employment the Moroccan banking system posts very important levels with alarming growth rates, indicating a retreat in the prospection of the deposits (figure 11).

In addition, the test of solvency is weakest in the majority of the countries of the zone MENA. This exposes it at the rather important risks of instability, though the deposit rate of the credits in suffering is largely high compared to the other countries. Improvements were noted on the level of the capital of the capable banks to increase their impact strength, however, the ratio of the stockholders' equity reported on the whole active moderate remainder and the level of solvency of the Moroccan banks and weakest since 2005 .

\subsection{Determinants of competition in Morocco: empirical evidence}

The interest carried to banking competition is justified by the fact that the positive externalities of a banking environment of pure competition and perfect have a direct impact on the ultimate consumer, the allowance of the resources and also the circulation of capital.

In this direction, analysis of banking competition with fact of arising that in addition to the banking behaviors, the basic characteristics of the financial system and economy significantly affect the degree of competition pre-established in a banking environment. From where need for identifying the explained factors being able and for determining competition within Moroccan banking industry.

One proposes in this point to evaluate the determinants of banking competition and this for on the one hand explaining why the banking system continues to post a structure of monopolistic competition and to evaluate the relevance of the policies undertaken by the Moroccan authorities since end of the year 90 , on the other hand.

The variables which were retained in order to trace the effects of public policies on the competition of the Moroccan banking system are: interbank interest rate, rate of economic growth, the rate of inflation, the credit-gap and the gap of the market capitalization brought back to the GDP. 
Figure 11. Position of Morocco compared to MENA zone (Indicating financial stability: equity to assets, credit to deposit, provision to NPL and solvability ratio)

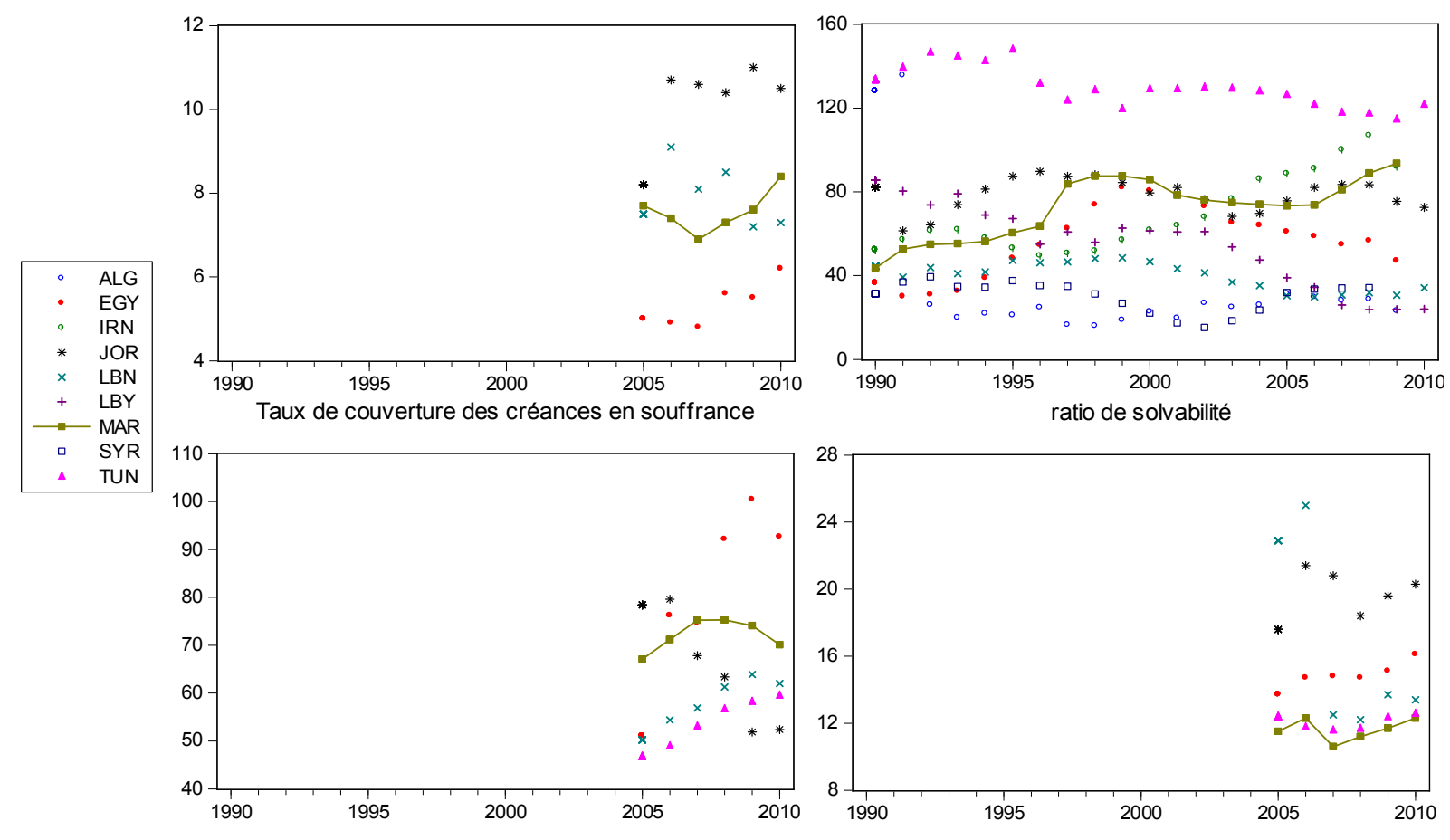

These variables are proxy's several regulatory and institutional policies which aimed to lead to a developed banking environment and whose competition is an identifiable feature:

- The degree of concentration: this indicator is theoretically essential to describe the level of competition. Indeed, the structure can have effects on competition of the banking system.

- For interest rate: it makes it possible to approximate the conditions of liberalization founded through the recourse to the legal and institutional reforms, since 1993.

- Rate of economic growth: allows to encircle advanced as regards the development economic ones and the conditions of creation of the added-value.

- The rate of inflation: it transcribes macro-economic balances and the conditions of conduits of the monetary policy.

- The credit-gap: it makes it possible to measure the combined effects of a development of the channel of financing by the credit and its effects on banking competition.

- Stock exchange-gap capitalization: it reflects the substitution effect and of competition between direct and indirect finance.

\subsubsection{Statistical Analyze of variables}

The series used during this analysis are annual data which recall the evolutions which marked the Moroccan banking environment during the period 1990-2010. The statistical properties of the variables are (table 1):

Table 1. Statistics of the variables of interest

\begin{tabular}{|c|c|c|c|c|c|c|c|}
\hline Statistic & \multicolumn{1}{|c|}{ H_PR } & \multicolumn{1}{|c|}{ TMP } & \multicolumn{1}{|c|}{ Y } & INFLATION & CRED_GAP & CAPI_GAP & IC_C \\
\hline Mean & 0.327433 & 0.051548 & 0.033948 & 0.026121 & $-8.03 \mathrm{E}-15$ & $-5.84 \mathrm{E}-15$ & $-7.72 \mathrm{E}-15$ \\
\hline Median & 0.327113 & 0.033718 & 0.032622 & 0.020420 & -0.000472 & -0.004489 & 0.009854 \\
\hline Maximum & 0.370471 & 0.122917 & 0.111564 & 0.061236 & 0.058212 & 0.231163 & 0.080594 \\
\hline Minimum & 0.291128 & 0.023858 & -0.067877 & 0.006198 & -0.055347 & -0.169536 & -0.105938 \\
\hline Std. Dev. & 0.019889 & 0.029297 & 0.046386 & 0.018202 & 0.036748 & 0.096224 & 0.046818 \\
\hline Skewness & 0.468781 & 1.136735 & -0.403614 & 0.678742 & -0.029425 & 0.494500 & -0.807969 \\
\hline Kurtosis & 2.799115 & 3.211936 & 2.664622 & 2.130037 & 1.898964 & 3.165679 & 3.106477 \\
\hline Jarque-Bera & 0.689534 & 3.692956 & 0.604909 & 2.058017 & 1.013120 & 0.837975 & 2.076221 \\
\hline Probability & 0.708385 & 0.157792 & 0.739002 & 0.357361 & 0.602565 & 0.657713 & 0.354123 \\
\hline
\end{tabular}


The analysis of the correlation enters the level of competition and the other macroeconomic indicator makes prevail the following relations (table 2):

Table 2. Stamp correlations

\begin{tabular}{|c|c|c|c|c|c|c|c|}
\hline $\begin{array}{c}\text { Correlations } \\
\text { matrix }\end{array}$ & H_PR & TMP (-1) & Y (-1) & $\begin{array}{c}\text { INFLATION } \\
\mathbf{( - 1 )}\end{array}$ & $\begin{array}{c}\text { CRED_GAP } \\
\mathbf{( - 1 )}\end{array}$ & $\begin{array}{c}\text { CAPI_GAP } \\
\mathbf{( - 1 )}\end{array}$ & IC_C \\
\hline H_PR & 1.000000 & & & & & & \\
\hline TMP (-1) & 0.377066 & 1.000000 & & & & & \\
\hline Y (-1) & -0.366079 & -0.082373 & 1.000000 & & & & \\
\hline INFLATION (-1) & -0.011664 & 0.590532 & -0.052861 & 1.000000 & & & \\
\hline CRED_GAP (-1) & -0.327574 & 0.017416 & -0.251523 & -0.243288 & 1.000000 & & \\
\hline CAPI_GAP (-1) & 0.171402 & 0.152393 & -0.159126 & 0.153552 & 0.359262 & 1.000000 & \\
\hline IC_C & -0.706750 & -0.263347 & 0.069522 & 0.257722 & -0.031646 & -0.281182 & 1.000000 \\
\hline
\end{tabular}

The index of competition of Panzar and Ross is negatively correlated with the whole of the indicators, but positively related on the evolution of the market cap and interbank interest rate. In this direction, one can advance that, the evolutions of interest rates on the money markets the fell down positive ones on the banking degree of competition. On the other hand, the market evolution stockbroker had positive effects on competitiveness within the banking system. This can be explained by the presence of the participations of banks, in the majority of the activities of the firms with dimensions capable to instigate competition between the banks to profit of more than profit. Moreover, by belonging to the credits floating the banking actions profit from the action leverages of the stock market what drains the banking behaviors towards more competition.

As regards the other variables, the opposite impact of the growth and credit compared to the GDP are justified by the fact that the changes or macroeconomic dynamics does nothing but reinforce the positions of the banks in the sector and do not lead them to lead more competition between it (figure 12). Indeed, this report is corroborated by the degree of concentration which is negatively correlated with competition. Thus, any rise of the concentration results in a fall of competition. This can be more interesting to visualize it using a graph describing the slopes between each indicators lasting all the period which knew the structural reforms engaged by Morocco.

Thus, the most important report relates to the relation between the degree of concentration and competition where it is noticed that between 1990 and 2010, the negative tendency tends more and more to be accentuated. What makes prevail a tendency towards a monopolistic structure, even if the policies which were followed aimed at making competition a fundamental characteristic of the banking system?

\subsubsection{Presentation of the model}

Following the example statistical analyzes, it arises that competition is significantly influenced by the macroeconomic and structural indicators. For this purpose, the model which is proposed aims at connecting these various reports in order to describe the impact of the policies led on banking competition to Morocco.

On this register, we suggest using an econometric model connecting the various variables. This approach is based on two stages:

- Initially, a linear modeling using least the square ordinary one is MENA. In this stage, one extracts elasticity's connecting the macroeconomic and structural indicators with the banking level of competition and analyzing us the results obtained and their implications in political matters.

- In the second time, analyzes of simulations are MENA using stochastic simulations under MATLAB and Dynare 4.2.5 by supposing that the independent variables are exogenous processes.

Before having the model and the results obtained, an analysis of the stochastic properties is necessary. 
Figure 12. Graphic relations between the various variables

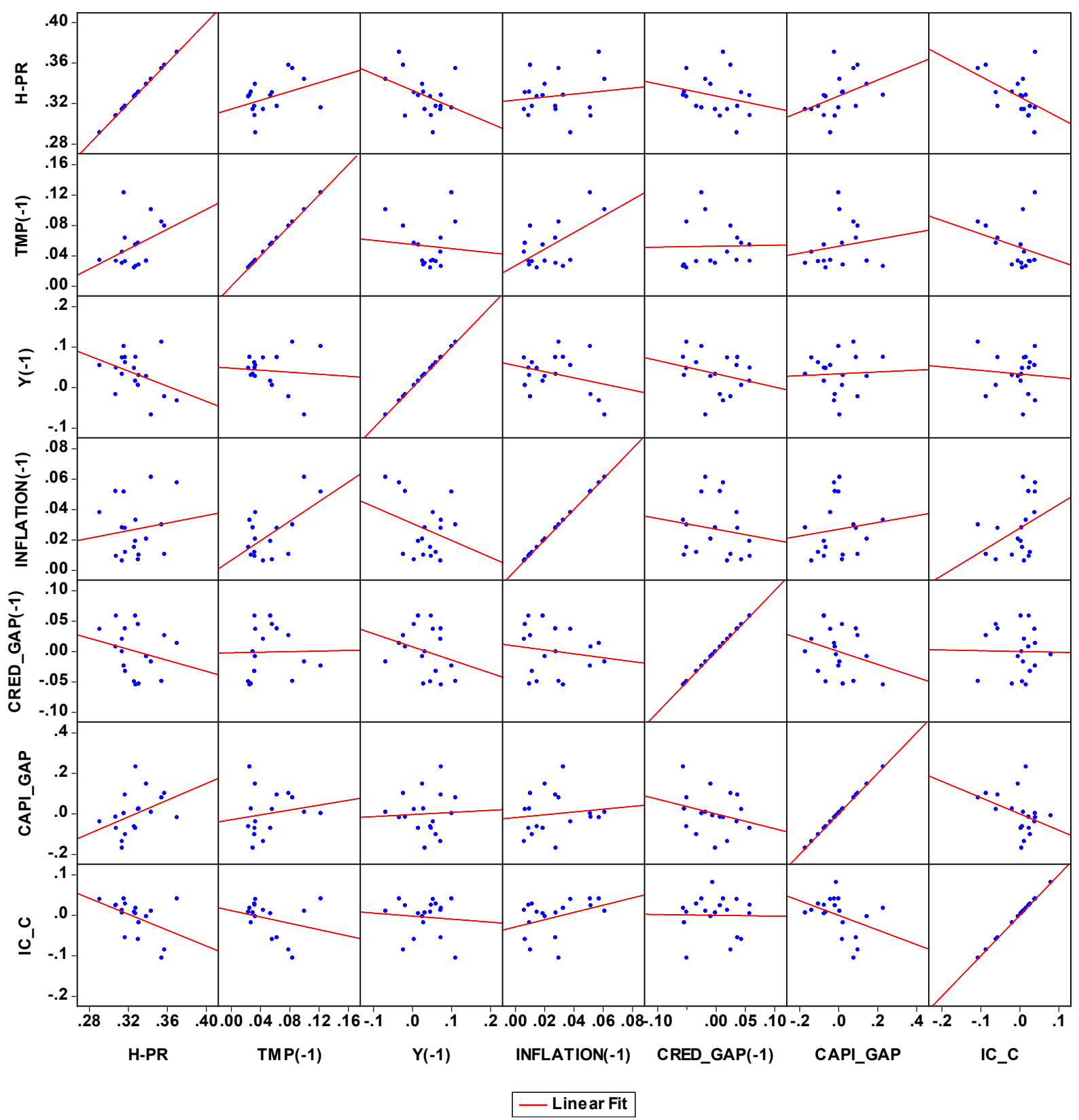

\subsubsection{Analyzes of stationnary}

The variables used are of two families:

- Level gauges: the case for the index of competition of Panzar and Rose and interbank interest rate, the rate of economic growth and the degree of concentration.

- Ratios: the credit and capitalization brought back to the GDP.

The usual indicators were the subject of unit test of root and it on the other hand brings out that they are stationary, the other indicators (ratios) are affected by tendencies what required the recourse to filters in order to extract the cycles (trend stationnary) (table 3). It should be noted that the degree of concentration is also a TS. The table gathers the results obtained after the correction of the tendencies within the various ratios.

Table 3. Unite root test

\begin{tabular}{|c|c|c|}
\hline United root test & Statistics & Probability ** \\
\hline ADF - Fisher Chi-square & 42.7261 & 0.0001 \\
\hline ADF - Choi Z-stat & -3.86684 & 0.0001 \\
\hline **significant at de 1\%
\end{tabular}


Thus and according to the results obtained, after the transmissions necessary to hold in account the existence of the deterministic tendencies, one confirmed that the series are not characterized by the existence of unit roots. From this point of view, one can suggest the use of a model of regression estimated with least the square ordinary ones (OLS).

\subsubsection{Results of the estimates}

By respecting the basic assumptions of the method of least squares ordinary, we proposed to estimate a model of the following form:

With;

$$
H_{\mathrm{t}}=Y_{\mathrm{t}}+T M P_{\mathrm{t}}+\text { Credg }_{\mathrm{t}}+C P g_{\mathrm{t}}+I c_{\mathrm{t}}+I n f_{\mathrm{t}}+\varepsilon_{\mathrm{t}}
$$

H: Index of competition of Panzar and Ross;

Y: Rate of economic growth;

Credg: Credit-gap;

CP: Stock exchange-gap capitalization;

Ic: Degree of concentration of the three large banks of the place;

Inf: Rate of inflation;

$\varepsilon$ : Residue;

The estimate is MENA on annual data over one period going of 1990 and 2010. The choice of this temporal dimension is justified on the one hand by the constraint of availability of the data and on the other hand by the need for integrating in our analysis the years of structuring reforms.

As we underlined, the method of the estimate most effective, according to the stochastic characteristics of the data is least the square ordinary ones. For this purpose, the results obtained after several tests of specifications are presented in the table 4:

Table 4. Estimates results

\begin{tabular}{|c|cc|}
\hline Variables & \multicolumn{2}{|c|}{ Coefficients } \\
\hline TMP (-1) & 0.224560 & $(0.01)$ \\
\hline Y (-1) & -0.169552 & $(0.00)$ \\
\hline INFLATION (-1) & -0.336298 & $(0.05)$ \\
\hline CRED_GAP (-1) & -0.198616 & $(0.00)$ \\
\hline CAPI_GAP & 0.035770 & $(0.06)$ \\
\hline IC_C & -0.160807 & $(0.00)$ \\
\hline Cte & 0.327400 & $(0.00)$ \\
\hline R-squared & \multicolumn{2}{|c|}{0.87} \\
\hline R-squared ajusted & \multicolumn{2}{|c|}{0.79} \\
\hline D.W. & \multicolumn{2}{|c|}{2.2} \\
\hline
\end{tabular}

The parameters obtained after the estimate affirm that there exists a significant relation between competition and the indicators macroeconomic and structural. In this direction, the macroeconomic evolutions and the transformations affecting the structure of banking industry have an impact on the banking degree of competition.

On the econometric level, the whole of the coefficients are significant and their critical probabilities are lower than $10 \%$. The coefficient of determination (R-square and adjusted R-square) confirms that the exogenous variables represent a big part in the explanation of the index of competition (table 5). In the same way, the test of autocorrelation of DW cancels the existence of positive or negative autocorrelation. Within this framework, the test of heteroscedasticity also confirms the absence of a volatility of the variance of the residues and consequently their stationaries.

Table 5. ARCH Test

\begin{tabular}{|c|r|c|c|}
\hline \multicolumn{4}{|c|}{ ARCH Test } \\
\hline F-statistic & 0.029276 & Prob. F(1,13) & 0.8668 \\
\hline Obs*R-squared & 0.033705 & Prob. Chi-Square(1) & 0.8543 \\
\hline
\end{tabular}


The normality of the residues is marked via the development of the distribution of the residues and also through the tests of normality (figure 13). Thus, the test of Jarque-Bera posts a value of 0.36 (0.86), which affirms that the residues follow a normal law. On this register, one can advance that the residues are white noise.

Figure 13. Distribution of the residues of the model

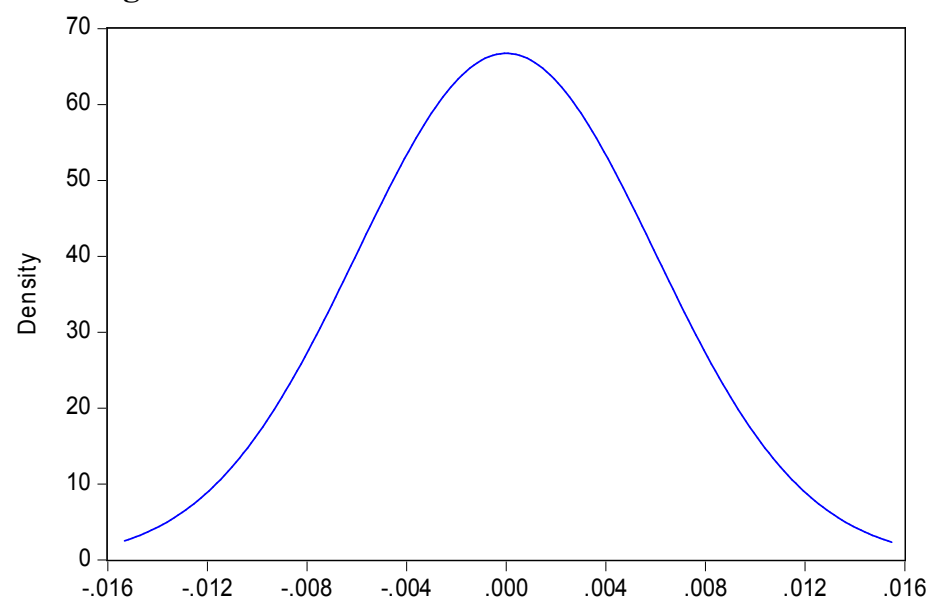

With regard to the analysis of the coefficients obtained and by taking account of the weakness of temporal dimension, the analysis of the robustness and the stability of the parameters revert an private interest.

In this direction, the recursive test of the estimate of the parameters indicates a stability of the coefficients during the whole of the period of estimate (figure 14). Thus, the coefficients are stabilized with their unbiased estimate as from 2005 indicating a reliable and consistent estimate.

Figure 14. Test of stability of the coefficients
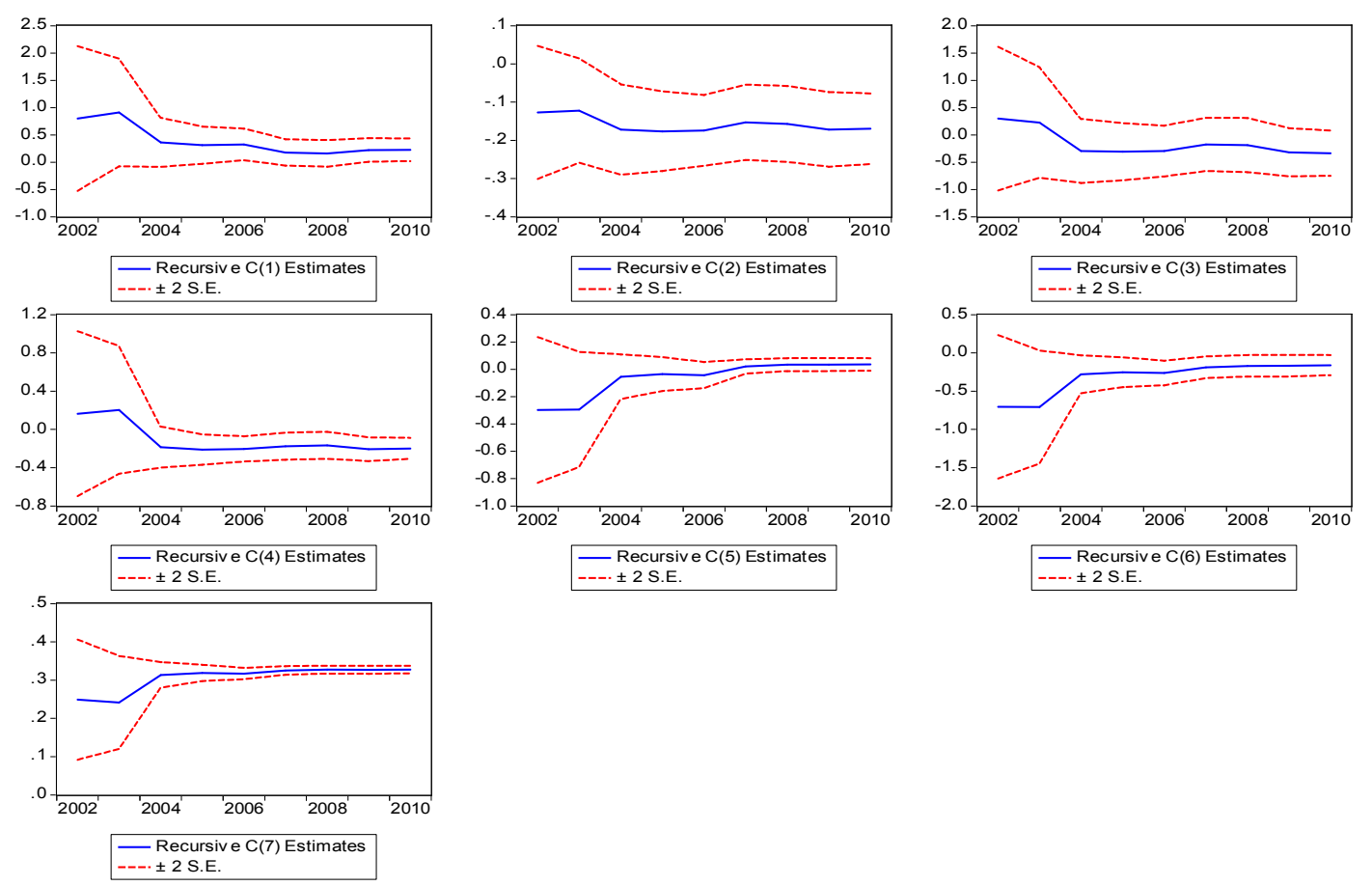

Also, another technique of validation was used; it acts in particular of the technique of boostraping, which makes it possible to lead simulations on the parameters in order to lead to the distributions of each parameter. For this purpose, 10000 simulations were MENA, to arrive at the results below, which confirms the effectiveness and the consistency of the parameters. 
On the economic plan, the results obtained provide an interesting range of analysis and comments:

- The positive relation between the index of competition and the concentration corroborates the theoretical intuitions. The structure very concentrated of the Moroccan banking system blocks the installation of a system competing.

- The economic growth is negatively correlated in the conditions of competition, that states unfortunately that when there is a constant economic growth the banks do not behave competing manner and try to preserve only their market share stimulated by a strong concentration of the sector. The same remark is valid for the variable bank credits.

- The market cap, indicator of finance direct, is of positive correlation with the index of competition what is in conformity with the liberal theory. Thus, the development or the recourse to the financial market accentuates competition between the banks to produce services being able to attract more customers in order to compensate for those having chosen the stock market.

- With regard to interbank interest rate, it is equipped with a plus coefficient, indicating a positive impact on competition. Thus, the falls recorded on the level of interest rate since the release made it possible to create a channel making improve competition on the banking environment. In this direction, only the channel of the cost of financing is considered most active to affect the degree of competitiveness of the banking environment, accompanied in that by the recourse to the stock market.

After obtaining the model describing the relation between the banking index of competition and the variables describing the macroeconomic and structural conditions. We planned in the second place to work out a model of simulation allowing describing the competing behavior of the banking system follows to the advent of the structural shocks. The objective is to identify the policies making it possible to guarantee a better competition and measurements to be implemented if necessary.

\subsubsection{Simulation and policy to be undertaken}

The equation which was estimated before considers that the variables independent of the macroeconomic conditions are exogenous, in this direction and sight that we chose a simple linear model, it is impossible to as well produce simulations and forecasts on the competing situation with the Moroccan banking environment.

Have regard to this report, it is necessary to adopt a structural form, where it is considered that the exogenous variables are structural variables which one can put under shock. Following the example work of simulations running, we chose Dynare 2.3.1 pennies MATLAB to constitute a structural model which makes it possible to simulate the various possible shocks. From this point of view, one chose the following presentation:

$$
\begin{aligned}
\mathrm{H}_{\mathrm{t}}=\mathrm{Y}_{\mathrm{t}}+\mathrm{TMP}_{\mathrm{t}}+\operatorname{Credg}_{\mathrm{t}}+\mathrm{CPg}_{\mathrm{t}}+\mathrm{Ic}_{\mathrm{t}}+\operatorname{Inf}_{\mathrm{t}}+\varepsilon_{\mathrm{t}} \\
Y_{t}=c_{1}+\sum_{i=1}^{p} \alpha_{i}(Y)_{t-i}+\psi_{t} \\
T M P_{t}=c_{2}+\sum_{i=1}^{p} \beta_{i}(T M P)_{t-i}+\zeta_{t} \\
\operatorname{Credg}_{t}=c_{3}+\sum_{i=1}^{p} \gamma_{i}(\text { Credg })_{t-i}+v_{t} \\
I c_{t}=c_{4}+\sum_{i=1}^{p} \varphi_{i}(\text { Ic })_{t-i}+\xi_{t} \\
\operatorname{capg}_{t}=c_{5}+\sum_{i=1}^{p} \varphi_{i}^{\prime}\left(\text { capg }_{t-i}+\gamma_{t}\right.
\end{aligned}
$$

With: $\varepsilon_{\mathrm{t}}, \psi_{t}, \zeta_{t}, v_{t}, \xi_{t}, \gamma$, are residues of the exogenous processes determining the degree of competition in Morocco 
The whole of the residues of the models are regarded as being random variables which follow a normal law and describes the effects of a public policy. The simulation of these shocks provided the results summarized in the table 6 hereafter:

Table 6. Answers to the economic shocks

\begin{tabular}{|c|c|}
\hline Types of shock & Responses \\
\hline Monetary policy (TMP) & Positive competition after a period of 2 years \\
\hline Supply shock (Y or Credg) & Negative after a period of 2 years \\
\hline Structural shock ( Ic) & Positive after a period of 2 years \\
\hline Stock market shock (cap_g) & Positive competition after a period of 2 years \\
\hline
\end{tabular}

In parallel, the analysis of the decomposition of the variance makes it possible to approach the most significant shocks impacting the banking degree of competition in Morocco (table 7).

Table 7. variance decomposition

\begin{tabular}{|c|c|}
\hline Chocs & Contribution to a variance \\
\hline TMP & $34 \%$ \\
\hline Growth of GDP & $18.4 \%$ \\
\hline Banking credit & $26 \%$ \\
\hline Stock market capitalization & $0.6 \%$ \\
\hline Index of concentration & $19 \%$ \\
\hline
\end{tabular}

Thus, one can affirm that the policies which aim at reducing the rates of financing of the banks are most likely to influence the degree of competition in the Moroccan banking system. From this point of view, the monetary policy is best placed to instigate competition on the level of the banking system. Also efforts must be deployed in order to return the structure of the banking system less concentrated to make it possible entering potential to resort to the Moroccan market. From this point of view of other policies must be refitted in that one notes the lawful policies and of regulation. In the same way, with regard to the development of the market of credit, this last remains with significant impact on the degree of competition, thus a strategy will have to be MENA for seizing opportunity well of guaranteeing a market with equitable access for each banking institution and of limiting the abuse of power by the banks of bigger size.

\section{Summary and Concluding Remarks}

The empirical results that this paper indicate that the degree of competition of the banking system is determined by several macroeconomic aggregates which make it possible to describe the policies undertaken on the financial plan in Morocco. Thus, the results obtained affirm that there exists a positive relation between the index of competition and the concentration what makes it possible to check our theoretical perception. So a structure very concentrated of the Moroccan banking system blocks the installation of a system competing. On another register, the economic growth is negatively correlated with competition, that states unfortunately that when there is a constant economic growth the banks do not behave competing manner and try to preserve only their market share stimulated by a strong concentration of the sector. This is tributary also for the conditions on the market of the credit, which indicates that when the request is constant the banks tend to have less competing behaviors. In addition, the development of the stock market impact positively competition what is in conformity with the liberal theory. Thus, the recourse to the financial market accentuates competition between the banks to produce services being able to attract more customers in order to compensate for those having chosen the stock market. Lastly, in the field of the implementation of the monetary policy, the indicator of interbank interest rate has a positive impact on competition. Thus, the falls recorded on the level of interest rate since the release made it possible to create a channel making improve competition on the banking environment. According to the results of the stochastic model of simulation, it arises that the policies to undertake in order to consolidate the competing degree of the Moroccan banking system are those affecting the rates of refinancing of the banks and those allowing influencing demand and on the market of the appropriations. 


\section{References}

Angelini, P., Cetorelli, N. (2003) The Effects of Regulatory Reform on Competition in the Banking Industry. Journal of Money, Credit and Banking, 35, 663-684.

Barth, J.R., Gerard, Caprio Jr., Ross, L. (2001) The Regulation and Supervision of Banks around the World: A New Database, In Integrating Emerging Market Countries into the Global Financial System, ed. by Robert E. Litan and Richard Herring, 183-241.

Berger, A N, R S Demsetz and P E Strahan (1999): "The consolidation of the financial services industry: causes, consequences, and implications for the future", Journal of Banking and Finance, 23, 135-94.

Besanko, D.A., Thakor, A.V. (1992) Banking Deregulation: Allocational Consequences of Relaxing Entry Barriers. Journal of Banking and Finance, 16, 909-932.

Bikker, J.A., Spierdijk, L., Finnie, P. (2007) Market Structure, Contestability and Institutional Environment: the Determinants of Banking Competition DNB Working Paper nr. 156, De Nederlandsche Bank, Amsterdam. Brookings-Wharton Papers on Financial Services, Brookings Institution Press.

Claessens, S., Laeven, L. (2004) What Drives Bank Competition? Some International Evidence. Journal of Money, Credit and Banking, 36, 563-584.

Claessens, S., Laeven, L. (2005) Financial Dependence, Banking Sector Competition, and Economic Growth Journal of the European Economic Association, March, No. 31, pp. 179-201.

Demirgüç-Kunt, A., Laeven, L., Levine, R. (2004) Regulations, Market Structure, Institutions, and the Cost of Financial Intermediation. Journal of Money, Credit, and Banking, 36(3), 593-622.

Fernández De Guevara, J., J. Maudos And F. Pérez (2005). Market power in European banking Journal of Financial Services Research, 27 (2), pp. 109-138.

Fernández de Guevara, J., Maudos, J. (2007) Explanatory Factors of Market Power in the Banking System. Manchester School, 75, 275-296.

Marshall, Alfred (1890). Principles of Economics.1 (First Edition). London: Macmillan, p.754

Maudos, J., Nagore, A. (2005) Explaining Market Power Differences in Banking: a Cross-country Study WP-EC 2005-10, Instituto Valenciano de Investigaciones Económicas, S.A.

Panzar, J.C. and J.N. Rosse, (1987). Testing for 'Monopoly' Equilibrium," Journal of Industrial Economics, Vol. 35, pp 443-456.

Petersen, M.A., Rajan, R.G. (1994) The Benefits of Lending Relationships: Evidence from Small Business Data. Journal of Finance, 49, 1367-400.

Santiago Carbó-Valverde \& José Manuel Liñares-Zegarra \& Francisco Rodríguez-Fernández, (2007). Market Power And Willingness To Pay In Network Industries: Evidence From Payment Cards Within Multiproduct Banking. FEG Working Paper Series 07/01, Faculty of Economics and Business (University of Granada)

Strahan, P. (2003) The Real Effects of US Banking Deregulation. Federal Reserve Bank of St. Louis Review, July/August 2003, No. 85, Vol. 4, 111-28.

\section{Annexes}

\section{Evolution of Panzar and Ross index (H)}

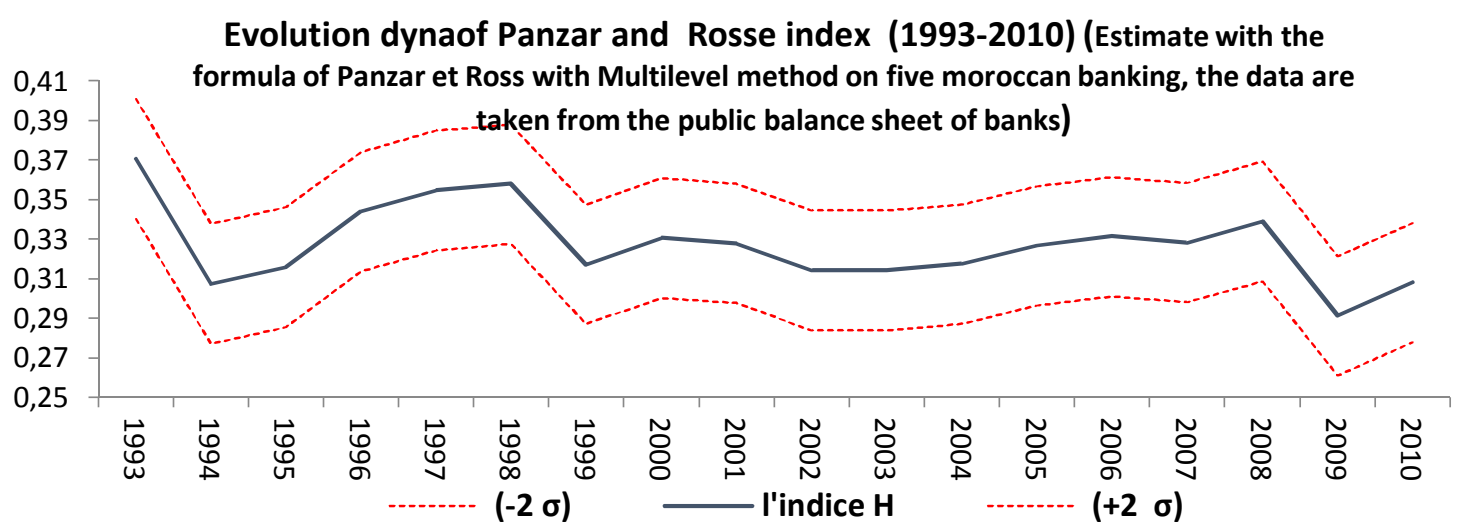

